\title{
Design an Information Management System for a Pharmacy
}

\author{
Hewa Majeed Zangana \\ Department of Computer Science / College of Computer Science and IT / Nawroz University / Kurdistan Region of Iraq
}

\begin{abstract}
This paper is insight into the design and implementation of a Pharmacy Management System. The primary aim of it, is to improve accuracy and enhance safety and efficiency in the pharmaceutical store. Today management is one of the most essential features of all form. Management provides sophistication to perform any kind of task in a particular form. This is pharmacy information management system; it is used to manage most pharmacy related activities in the pharmacy.
\end{abstract}

Keywords: Pharmacy, Management, Information, System

\section{INTRODUCTION}

Pharmacy management system is a management system that is designed to improve accuracy and to enhance safety and efficiency in the pharmaceutical store. It is a computer based system which helps the Pharmacist to improve inventory management, cost, medical safety etc. The system allows the user to enter a manufacturing and expiry date for a particular product or drug during opening stock and sales transaction. The system will also give report showing the list of products expiry after a specified date before the product eventually expires. It also involves manual entry upon arrival of new batches of drugs and upon drug movement out of the pharmacy for a certain period, e.g. every month, the pharmacist may want to generate report for the movement of drugs in and out of the pharmacy, getting information about the drugs e.g. expiry date, date purchased, number of drug type left, location of a drug in the pharmacy. At present, manual system is being utilized in the pharmacy. It requires the pharmacist to manually monitor each drug that is available in the pharmacy. This usually leads to mistakes as the workload of the pharmacist increases.

\section{STATEMENT OF THE PROBLEM}

Pharmacy management has kept paper record in filing cabinets. Managing a very large pharmacy with records on papers will be tedious and difficult to keep track of inventories with regards to the drugs in the store, expiry date, quantity of drugs available based on the categories and their functions. The pharmacist has to order drugs to replenish the already diminishing stock. In addition, ordering of drugs is being carried out manually. Significant amount of time is allocated for writing the order as the pharmacist needs to go through the stock balance and make rough estimate of the amount to order based on Figures. Drugs are not supposed to be used after they have expired. This project work will prompt the pharmacist about drugs that are close to expiry, preventing those drugs from being sold and also providing solution to the earlier stated problems.

The proposed system is as follows:

\section{Proposed System}

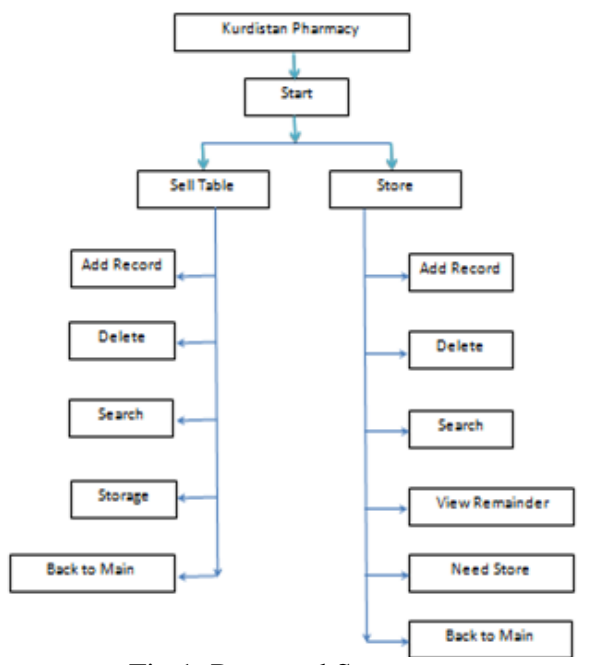

Fig.1: Proposed System 
International Journal of Advanced Research in Computer and Communication Engineering

Vol. 7, Issue 10, October 2018

The system for pharmacy begins like follows:

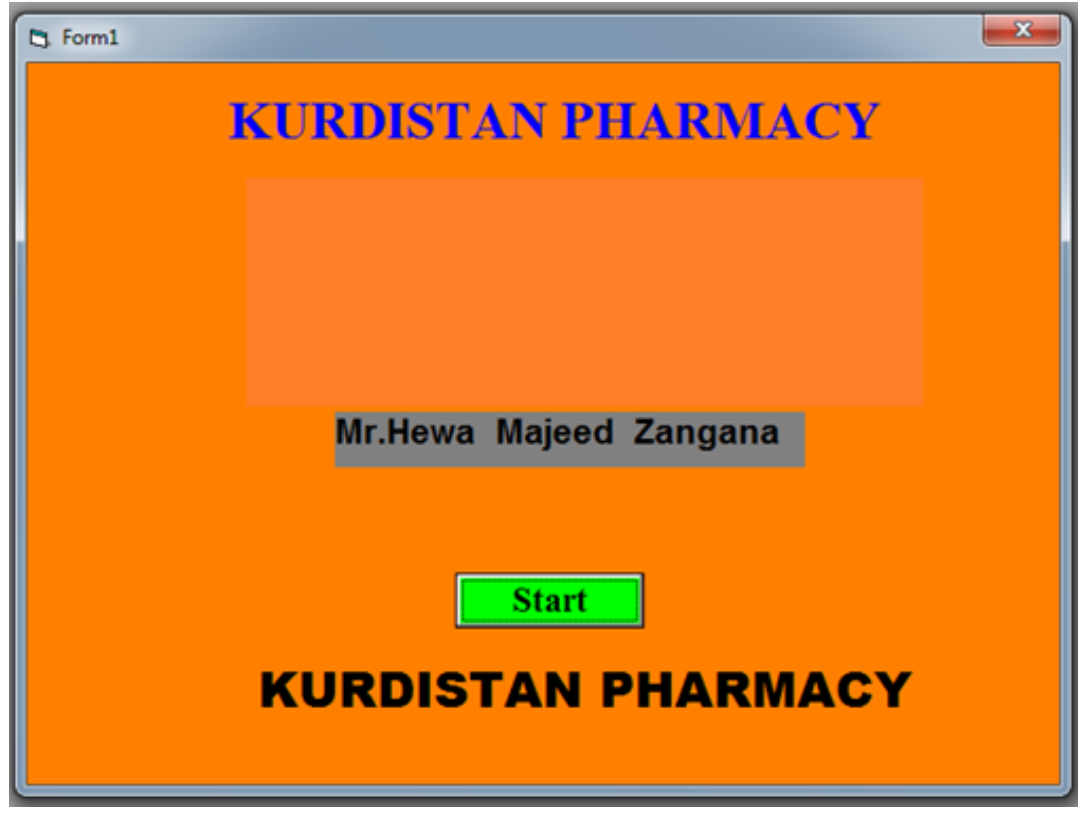

Fig. 2: Front page for the system of pharmacy

At first running show this form. We can "start" in our program by this form. This form has one command. We can enter to the program if clicking start command.

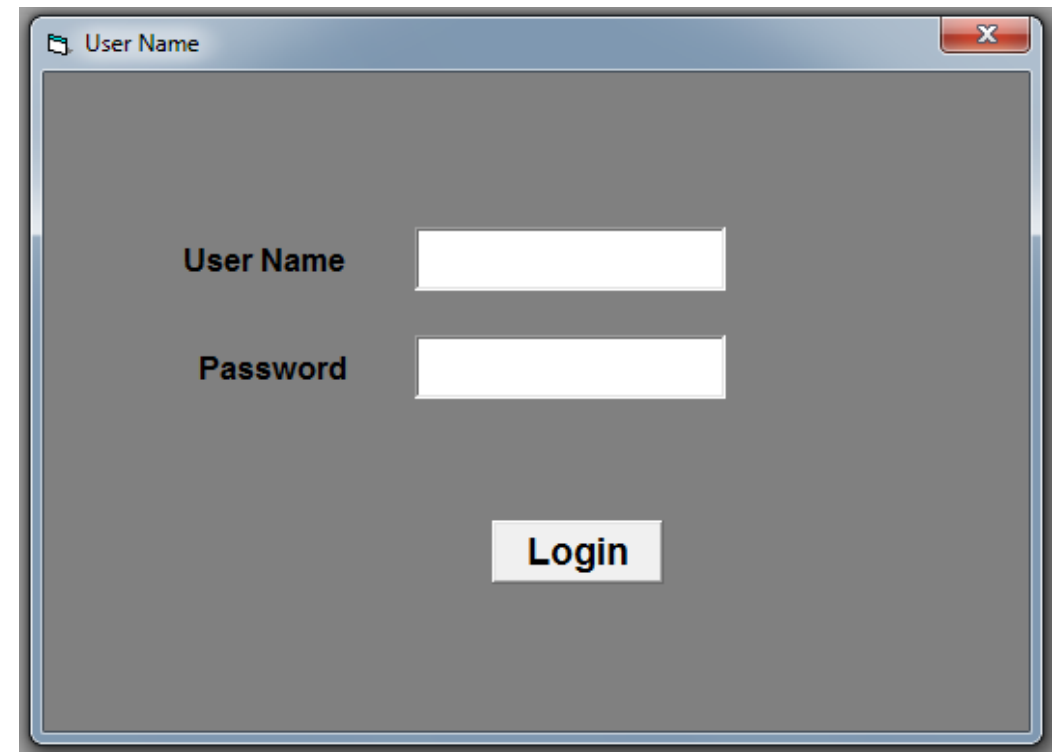

Fig.3: User Name and Password Form

In this form we have one command "login" and two text box the "user name" used to entering user name and the second use to entering the password then we can click on the login to opening the main form. 


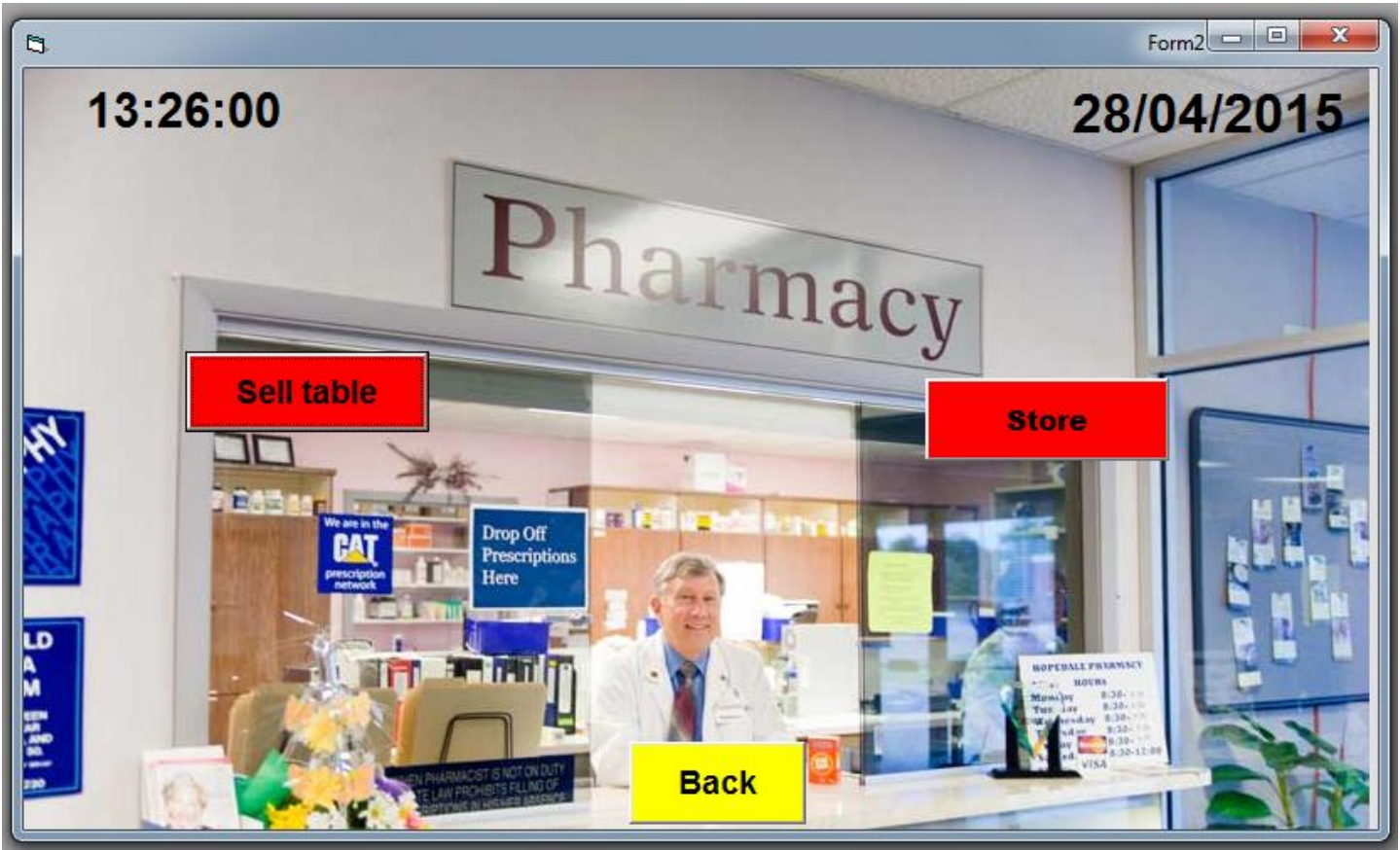

Fig. 4: The Main Form

This form consist of three commands . the first we named (sell table) that contain the account sell of the medicine, and the second (store) contains the customer and the company medicin account, and the third used to back for to start form.

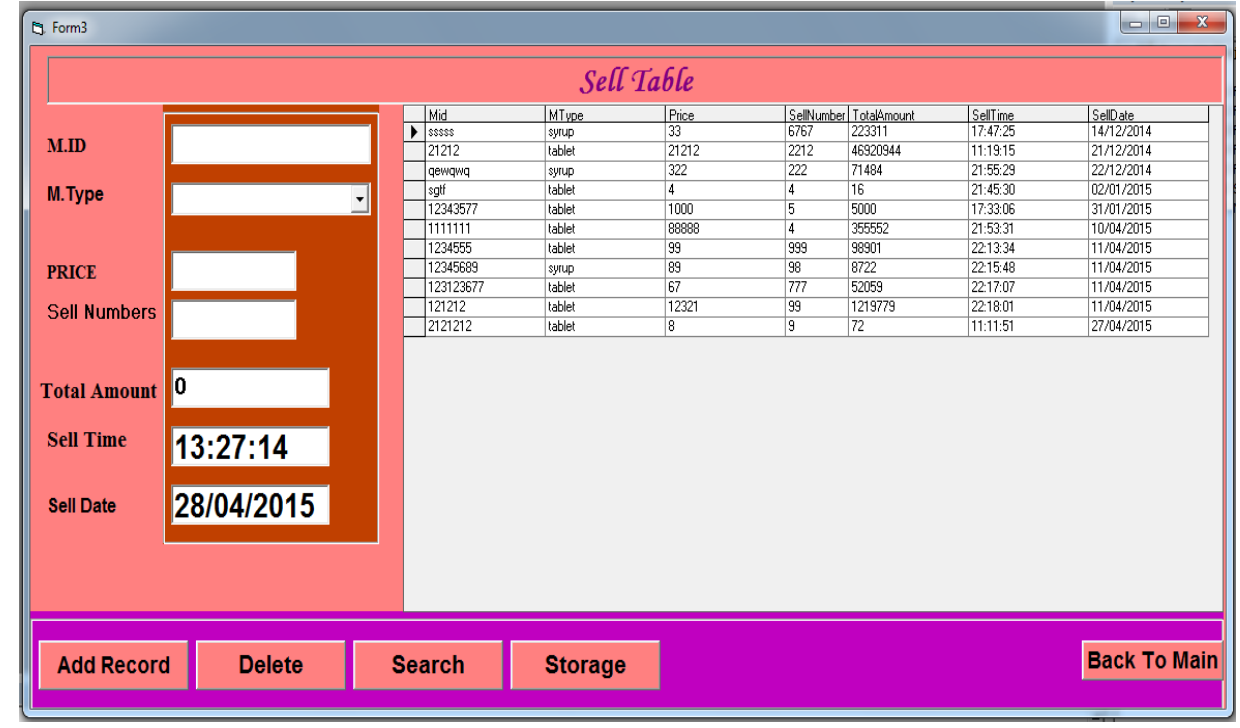

Fig. 5 Sell Table Form

This is accounting sell table form. In this form we have six textboxes and five commands and one combo box and one data grid. in "Letter" textbox enter medicine ID and price of medicine and sell number and the total amount giving us last cost by multiplying price with sell numbers, sell time and sell date displaying the time and date of selling medicine, the combo box determining the type of medicine .the "Add Record" command use for add that information you entered in textbox and save it in your database and display it in data grate. And the "Delete" command used for delete the record in your database and data grate the search command used to finding the required medicine, and "Storage" command represent that existing data in database at data grid. And the "back to main" command used to back and display the main form. 


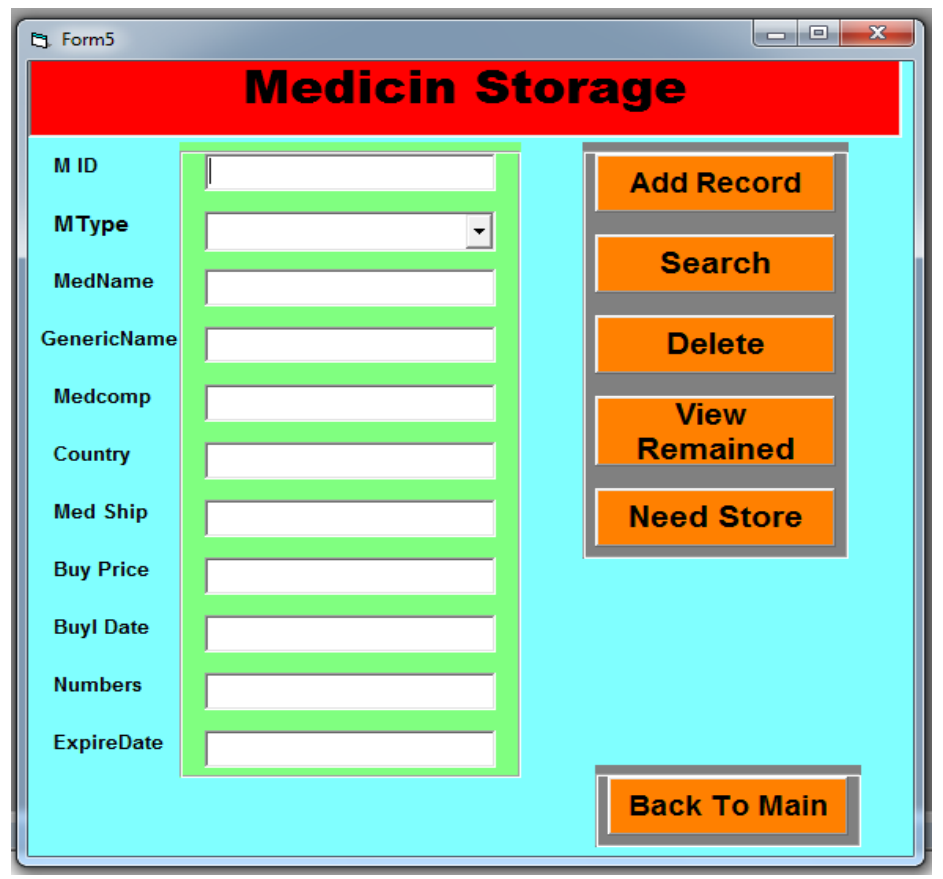

Fig. 6: Medicine Storage Form

In this form we have three frame, the first contain ten textbox and one combo box , the text boxes its medicine ID ,medicine type ,medicine name, generic name , ,medicine company ,country of ,medicine made , ,medicine ship , buying price of ,medicine, date of buying, numbers of ,medicine and expired date of medicine. The second frame contain five commands, "Add Record" command use for add that information you entered in textbox and save it in your database and display it in data grate, And the "Delete" command used for delete the record in your database and data grate .the search command used to finding the required medicine, and the "View Remainder" use to display our medicine in data base table, and the Command "Need Store" use to viewing what's the need of store data base table, last command in third frame used to back and display the main form.

\section{CONCLUSIONS}

Effective implementation of this software will take care of the basic requirements of the pharmacy management system because it is capable of providing easy and effective storage of information related to activities happening in the stipulated area. With these, the objectives of the system design will be achieved. In order to allow for future expansion, the system has been designed in such a way that will allow possible modification as it may deem necessary by the pharmacy management, whenever the idea arises.

\section{SUGGESTIONS FOR FUTURE WORK}

Designing this application (Pharmacy management system) is not an easy task. It all started from the requirement gathering and passes through so many other stages before completion. Based on the benefits of this system and tremendous value it will add to customer-user satisfaction, the below recommendation will be considered; It is recommended that the new system should be used with the necessary specifications of the system requirements and provision for an uninterrupted power supply should be made available throughout the hours of operation of the pharmacy to avoid power outage. There should also be basic computer knowledge for the users of the software. It is recommended that the software be improved especially in areas of accounting as it will be of great impact to the development of retail pharmacy.

\section{REFERENCES}

[1]. Barbara Griggs. Green Pharmacy: The History and Evolution of Western Herbal Medicine, Second Edition. Viking press, (1982). Pg 93-97.

[2]. Charles E. Rosenberg, Morris J. Vogel. The Therapeutic Revolution: Essays in the social history of American Medicine, Second Edition. University of Pennsylvania press, (1979).Pg 174.

[3]. Peter G Homan, Briony Hudson, Raymond C Row. Popular Medicines: An illustrated

[4]. Leslie G. Mathews. History of Pharmacy in Britain. Edinburgh, E\&S. Livingstone(1962). Pg 213-223.

[5]. History, Fourth Edition. Trade paperback, Pharmaceutical press (2008).Pg. 127.

[6]. Stuart Anderson. Making Medicines: A Brief History of Pharmacy and Pharmaceuticals, Sixth Edition .Jessica Kingsley publisher, (2005).Pg 214

[7]. Charles E. Rosenberg. History of Medicine and Allied Sciences, Seventh Edition. University of Pennsylvania press, (2003).Pg 197.

[8]. George A. Bender. Great moments in Medicine, Cambridge university press (1967). Pg 118. 